\title{
Effects of pre-exercise ingestion of a carbohydrate-electrolyte gel on cycling performance
}

\author{
Mark ET Willems', Chris DJ Toy, Andrew M Cox \\ From International Society of Sports Nutrition: 8th Annual ISSN Conference and Expo \\ Las Vegas, NV, USA. 24-25 June 2011
}

\section{Background}

Exercise performance can benefit from pre-exercise ingestion of carbohydrate-electrolyte drinks. Carbohydrate-electrolyte gels may provide a convenient and effective energy source for subsequent exercise bouts, but supportive evidence needs to be provided. We examined the effect of pre-exercise ingestion of a commercial carbohydrate-electrolyte gel on cycling performance.

\section{Methods}

Following an overnight fast, healthy males ( $\mathrm{n}=12$, age: $24 \pm 7$ yr, height: $181 \pm 6 \mathrm{~cm}$, body mass: $78.1 \pm 9.4 \mathrm{~kg}$, $\left.\mathrm{VO}_{2 \max }: 47.6 \pm 7.1 \mathrm{~mL} \cdot \mathrm{kg}^{-1} \cdot \mathrm{min}^{-1}, \mathrm{~W}_{\text {max }}: 316 \pm 51 \mathrm{~W}\right)$ cycled steady state $\left(40 \mathrm{~min}, \mathrm{SS} 1,56 \pm 4 \% \mathrm{~W}_{\max }\right.$, SRM Ergometer) followed by a time trial (15 min, TT1,Wattbike cycle ergometer), a 2 hour passive recovery, and cycled steady state (20 min, SS2, power equal to SS1) followed by a time trial ( $15 \mathrm{~min}$, TT2). Participants ingested either placebo ( $\mathrm{P}$, low-caloric gel, equal in flavour) or Maxifuel's Viper ${ }^{\mathbb{B}}$ Active Gel (V, 65 gram equal to one gel) (Maxinutrition Ltd, Hemel Hempstead, UK), $15 \mathrm{~min}$ pre-SS1 $(+250 \mathrm{ml}$ water $), 0 \mathrm{hr}$ post-TT1 $(+750$ $\mathrm{ml}$ water), $1 \mathrm{hr}$ post-TT1 (+250 $\mathrm{ml}$ water), and $15 \mathrm{~min}$ pre-SS2 (+250 ml water). Maxifuel's Viper ${ }^{\circledR}$ Active Gel contains $22 \mathrm{~g}$ maltodextrin, $11.2 \mathrm{~g}$ sucrose, $1.5 \mathrm{~g}$ dextrose, $0.8 \mathrm{~g}$ fructose and $0.1 \mathrm{~g}$ sodium per $100 \mathrm{~g}$ ). Experimental design was double-blind and randomized. Carbohydrate oxidation was calculated with stoichiometric equations from Jeukendrup \& Wallis. Two-way ANOVA with post-hoc t-tests were used for analysis with significance accepted at $\mathrm{p}<0.05$.

\footnotetext{
* Correspondence: M.Willems@chi.ac.uk

Department of Sport and Exercise Sciences. University of Chichester, United Kingdom
}

\section{Results}

During SS1, heart rate, oxygen uptake, respiratory exchange ratio, rating of perceived exertion, plasma lactate and carbohydrate oxidation were not different between conditions. There was a trend for blood glucose $\left(\mathrm{mmol} \cdot \mathrm{L}^{-1}\right)$ with Viper during SS1 to be higher at $0 \mathrm{~min}$ $(\mathrm{P}: 4.26 \pm 0.21, \mathrm{~V}: 6.36 \pm 0.76)$ and $10 \mathrm{~min}(\mathrm{P}: 3.89 \pm$ $0.37, \mathrm{~V}: 4.98 \pm 0.70$ ), and lower at $20 \mathrm{~min}(\mathrm{P}: 3.89 \pm$ $0.47, \mathrm{~V}: 3.12 \pm 0.69)$ and $30 \mathrm{~min}(\mathrm{P}: 3.92 \pm 0.45, \mathrm{~V}: 3.12$ \pm 0.69). During SS2, heart rate, oxygen uptake, rating of perceived exertion and plasma lactate were not different between conditions. Blood glucose (in $\mathrm{mmol} \cdot \mathrm{L}^{-1}$ ) with Viper during SS2 was higher at $0 \mathrm{~min}(\mathrm{P}: 3.80 \pm 0.40$, V: $5.33 \pm 0.77)$ and $10 \mathrm{~min}(\mathrm{P}: 3.56 \pm 0.40, \mathrm{~V}: 4.10 \pm 0.55)$. Respiratory exchange ratio was higher during SS2 for Viper at 5 min (P: $0.90 \pm 0.09$, V: $0.99 \pm 0.08$ ). Carbohydrate oxidation $\left(\mathrm{g} \cdot \mathrm{min}^{-1}\right)$ during SS2 was higher with Viper at $5 \mathrm{~min}$ (P: $2.11 \pm 0.84, \mathrm{~V}: 2.97 \pm 0.71)$. Cycling distance during TT1 and TT2 was 3.1\% (P: $9467 \pm 963$ $\mathrm{m}, \mathrm{V}: 9741 \pm 817 \mathrm{~m})$ and $3.4 \%(\mathrm{P}: 9375 \pm 943 \mathrm{~m}, \mathrm{~V}$ : $9667 \pm 746 \mathrm{~m}$ ) higher with the carbohydrate-electrolyte gel ingestion.

\section{Conclusion}

It is concluded that pre-exercise ingestion of a 65 gram commercial carbohydrate-electrolyte gel with multiple carbohydrates benefits cycling performance. In addition, the ingestion of the carbohydrate-electrolyte gel during recovery enhanced subsequent cycling performance. The consumption of commercial carbohydrate-electrolyte gels with different carbohydrates may be beneficial for athletes with multiple daily training sessions. 


\section{Acknowledgements}

Supplements were provided by Maxinutrition Ltd (Hertfordshire, UK). After

study completion, funding for conference attendance was obtained from

Maxinutrition Ltd (Hertfordshire, UK).

Published: 7 November 2011

\section{Reference}

1. Jeukendrup, Wallis : 2005.

doi:10.1186/1550-2783-8-S1-P28

Cite this article as: Willems et al:: Effects of pre-exercise ingestion of a

carbohydrate-electrolyte gel on cycling performance. Journal of the

International Society of Sports Nutrition 2011 8(Suppl 1):P28.

Submit your next manuscript to BioMed Central and take full advantage of:

- Convenient online submission

- Thorough peer review

- No space constraints or color figure charges

- Immediate publication on acceptance

- Inclusion in PubMed, CAS, Scopus and Google Scholar

- Research which is freely available for redistribution

Submit your manuscript at 